\title{
UNDERSTANDING COVID-19 DISPERSION IN THE FILIPINO SOCIOCULTURAL CONTEXT
}

\author{
Laurence Lascuña Garcia', Joana Mariz Castillo', Jillian Bejoc', Ernyl Henry Redulal,
} Ma. Mayla Imelda Lapa', Daisy Palompon'

1. Cebu Normal University, Cebu City, 6000, Philippines

Correspondence: garcial@cnu.edu.ph

\begin{abstract}
This study aims to discover the sociocultural factors affecting the disease dispersion pattern of the COVID-19 in the Philippines. This is an ecological study where the unit of observation is the cases of COVID-19 in the country. The cases compared was defined in various ways to create an explanation of the dispersion pattern of COVID-19 in the country. Data was taken from the official reports of the Philippine Department of Health as of March 13, 2020, on the 52 confirmed cases of COVID-19 in the country. Data gathered from the reports were age, sex, existing diseases, acquisition (local or international), proximity to carrier and health status. Results revealed that older male Filipinos are at higher risk of acquiring COVID-19 with prognosis defined by certain culturally-related diseases. The dispersion of the disease in the country is further compounded by the sociocultural context the Filipinos are in.
\end{abstract}

\section{KEYWORDS}

COVID-19, Social Behaviour, Sociocultural Factors, Infectious Disease, Public Health

\section{BACKGROUND}

Historically, scientists trying to anticipate the trajectory of infectious diseases focused on properties of the agent itself, like its level of contagion and lethality. But infectious diseases need help to spread their misery: humans meeting humans, in person. [1] An infection occurs when a microorganism survives and multiplies within another, usually larger, organism. To trigger infection, pathogens must first reach the host, where they may survive unnoticed unless an internal or external event triggers the disease. In most cases, pathogens reach the human host from the external environment through a variety of transmission systems. [2]

The novel SARS-CoV-2 coronavirus that emerged in the city of Wuhan, China, last year and has since caused a large scale COVID-19 epidemic and spread to more than 70 other countries. [3] Conventional routes of transmission of SARS-COV, MERS-COV, and highly pathogenic influenza consist of respiratory droplets and direct contact, mechanisms that occur with SARS-CoV-2 as well. Majority of the patients affected had visited a city, or had contact with city residents infected with the virus. These findings echo the latest reports, including the outbreak of a family cluster and transmission from an asymptomatic patient. [4] These behaviors further lead to disease dispersion when there is weakened disease defense potential due to natural causes like ageing process or presence of underlying health conditions. This can be further increased by the host behavior as described through host travel and the number of contacts. [5]

Despite dealing with biomedical practices, infection prevention and control is essentially a behavioural science. Human behaviour is influenced by various factors, including culture. Hofstede's model of cultural dimensions proposes that national cultures vary along consistent dimensions 
which can be grouped and scored as specific constructs. [6] In the past decade or so, leading investigators have begun to incorporate social networks into their models, trying to identify and analyze patterns of individual behavior that amplify or mute potential pandemics. [1] The introduction of diseases to a country with myriads of human inhabitants like the Philippines is consequence of various factors which includes social and cultural. There is a need to understand health and disease, not only through the medical science, but also through social science within the sociocultural context. [7] It is in these contexts, that this study is undertaken. This primarily aimed to provide understanding on how the COVID-19 spread in the Philippines looking into consideration the characteristics of people infected by the virus.

\section{DATA AND METHODS}

The study is an ecological study where the unit of observation is the cases of COVID-19 the country. The cases compared was defined in various ways to create an explanation of the dispersion pattern of COVID-19 in the country. Data was taken from the official reports of the Philippine Department of Health as of March 13, 2020 on the 52 confirmed cases of COVID-19 in the country. These are summarized reports about the individual cases of COVID-19 with specific characteristics of each case. The data gathered from the reports were age (actual age reported), sex (1 - Male; 2 - Female), presence of existing diseases $(1$ - immunocompromised; 2 - with lifestyle disease/s; 3 - unknown), acquisition (through 1 - local or 2 - international travel), proximity to carrier ( 1 - spouse; 2 relative; 3 - others); and health status ( 1 - dead; 2 - critical; 3 - stable; 4 - recovered). The data were analyzed using cluster analysis since there is no prior information about the group or cluster membership for any of the objects. The data was grouped into three clusters with the aid of SPSS. The analysis of the clusters was based on the judgment of the researcher and interpreted in terms of cluster centroids with the cluster closest to the Grand Centroid as basis for the interpretation.

\section{RESULTS}

The results of the cluster analysis presented in Table 1 led to the formulation of hypotheses.

\section{TABLE 1: CLUSTER ANALYSIS}

\begin{tabular}{lllll} 
VARIABLE & CLUSTER 1 & CLUSTER 2 & CLUSTER 3 & $\begin{array}{l}\text { GRAND } \\
\text { CENTROID }\end{array}$ \\
\hline Age & 50.3913 & 71.8421 & 29.5 & 54.2115 \\
Sex & 1.3043 & 1.5263 & 1.2 & 1.3654 \\
Existing Diseases & 2.8696 & 2.9474 & 2.8 & 2.8846 \\
CoviD-19 Acquisition & 1.4348 & 1.2632 & 1.5 & 1.3846 \\
Proximity to Carrier & 2.4783 & 2.1579 & 2.9 & 2.4423 \\
Health Status & 2.8261 & 2.5789 & 3.0 & 2.7692
\end{tabular}

Codes: Age (actual age reported), Sex (1 - Male; 2 - Female), Existing Diseases ( 1 - immunocompromised; 2 - with lifestyle disease/s; 3 - unknown), COVID19 acquisition (through 1 - local or 2 - international travel), Proximity to Carrier ( 1 - spouse; 2 - relative; 3 - others); Health Status ( 1 - dead; 2 - critical; 3 stable; 4 - recovered)

Table 1 focusing on Cluster 1 revealed that in terms of age, Filipinos affected with COVID-19 are in their 50s within the range of 40-60 years old. Majority of them are males with pre-existing lifestyle diseases. They acquired the disease through travel in affected cities within the country and through close continuous contact with relatives or housemates. Good to note is that even with the infection, health status is stable.

\section{DISCUSSION}

COVID-19 is a new disease and researchers are still learning how it spreads, the severity of illness it causes, and to what extent it may spread. Some factors can affect the risk of coming into contact with the virus, while other factors can affect the risk of developing severe illness. It is noted that older adults, 65 years and older, are at higher risk for severe illness. [8] But it affects other age groups also, only that 
those younger age groups affected may have good prognosis over others, as what the data in this study suggested.

Majority, have a stable condition. With those having older ages and pre-existing conditions succumbing to death. This is also true to other similar illnesses. Age is the most significant risk factor for increased seasonal influenzarelated mortality, with $90 \%$ of seasonal influenza-related deaths occurring in individuals over the age of 65 years. [9] It is more frequent in older adults to have comorbid conditions. Many comorbid conditions, both the number and type of comorbid conditions, predispose people to infections. [10] Furthermore, individuals at highest risk for severe disease and death include people with underlying conditions such as hypertension, diabetes, cardiovascular disease, chronic respiratory disease and cancer. Specifically, patients with comorbid conditions had much higher crude fatality rates: $13.2 \%$ for those with cardiovascular disease, $9.2 \%$ for diabetes, $8.4 \%$ for hypertension, $8.0 \%$ for chronic respiratory disease, and $7.6 \%$ for cancer. [11] Similarly, in a study which included 1099 patients with confirmed COVID-19, three of the most common comorbidities are hypertension (15\%), diabetes mellitus (7.4\%), and coronary heart diseases (2.5\%). [4] In addition, out of the 140 patients infected with SARS-CoV-2 in Wuhan, China, hypertension (30.0\%) and diabetes mellitus (12.1\%) were the most common comorbidities. [12] Among the most common disease of the Filipinos are lifestyle diseases they acquired due to a lot of cultural practices, making them more susceptible to this new disease.

It is also notable that in this study, males are most affected. The factors that might account for the sex differences in infectious diseases in humans are multiple, and include social, behavioral and biological factors. [13] Incidences of higher infection in men may be attributed to behavioral factors as well as biological factors particularly on how sex hormones regulate the immune response of the body. [14] Gender influences both patterns of exposure to infectious agents and the treatment of infectious disease. For example, gender roles influence where men and women spend their time, and the infectious agents they come into contact with, as well as the nature of exposure, its frequency and its intensity. [15] The differences in the susceptibility to infectious diseases between adult males and females can be ascribed more to their varied exposures rather than on biological attributes. [16]
One of the common differences that may influence the exposure patterns and treatment is the time spent from home and away from home. In most societies, males spend more time away from home leaving them more exposed to infectious agents outside the home while females tend to have more exposure to infectious agents inside the home. Another factor that influences exposure patterns and treatment is the responsibility of taking care of the sick. Females tend to get the role of "care-giving" in the home and in healthcare institutions than males exposing them to more infectious agents. [15] In this case, despite societal evolution, majority of the Filipino men take the role of a breadwinner making them go out of the house to find means of supporting the needs of the family. It is also assumed that those affected with the disease are men with high position in their areas of work allowing them to travel and get in contact with people, like business owners or company managers.

In addition, a study using single-cell sequencing, found that expression of ACE2 (the receptor for severe acute respiratory syndrome coronavirus 2 [SARS-CoV-2]) was more predominant in Asian men, which might be the reason for the higher prevalence of COVID-19 in this subgroup of patients than in women and patients of other ethnicities. [17]

SARS-CoV-2 spreads from person to person through close communities. When people with COVID-19 breathe out or cough, they expel tiny droplets that contain the virus. These droplets can enter the mouth or nose of someone without the virus, causing an infection to occur. The most common way that this illness spreads is through close contact with someone who has the infection. Close contact is within around 6 feet. [8] This is supported by the data in the study wherein the close continuous contact with an infected family member induced the increase in number of infected.

The disease is most contagious when a person's symptoms are at their peak. And, it is innate in Filipinos to care for their sick family members making them more vulnerable to acquiring the disease. However, it is possible for someone without symptoms to spread the virus. A new study suggests that $10 \%$ of infections are from people exhibiting no symptoms. Droplets containing the virus can also land on nearby surfaces or objects. Other people can pick up the virus by touching these surfaces or objects. Infection is likely if the person then touches their nose, eyes, or mouth. [8] It can still be linked to the Filipino close family ties. Most 
activities within the day, including meals, are to be shared by all members. Practices like kissing the hands exposes everyone to acquiring the disease from an asymptomatic family member.

Filipinos tend to be very sociable people, wherein every opportunity to gather is grabbed, take for example attendance to religious events, lunch outs during Sundays, visits to relatives and attendance to parties. It is noted in the data, that the cases are concentrated in certain areas. These areas are centers of urbanization and trade where a lot of people converge. The risk of coming into contact with the virus depends on how far it has spread in a person's local area.

The virus that causes COVID-19 seems to be spreading easily and sustainably in the community ("community spread") in some affected geographic areas. Community spread means people have been infected with the virus in an area, including some who are not sure how or where they became infected. The WHO state that the risk of developing COVID-19 is still low for most people. However, this is changing as the virus spreads. The risk is higher for anyone in close contact with people who have COVID-19, such as healthcare workers. Viruses can also spread more in certain areas, such as highly populated cities. [8]

The discussion of these factors, however, is based on inferences taken from the limited data available online, without actually going into in-depth data gathering per case. There are weak assumptions presented, but this allowed an investigation of the phenomenon of the COVID-19 dispersion using the sociocultural context as a basis, leading to understanding and more exhaustive explorations.

\section{CONCLUSION}

Thus, older male Filipinos are at higher risk of acquiring COVID-19 with prognosis defined by certain culturallyrelated diseases. The dispersion of the disease in the country is further compounded by the sociocultural context the Filipinos are in. It is then recommended that cultural practices of Filipinos be looked into in crafting policies to contain the dispersion of the disease and for effective programs to be implanted.

\section{References}

1. Carey B. Mapping the Social Network of Coronavirus. The New York Times; 2020. Available from: https://www.nytimes.com/2020/03/13/science/corona virus-social-networks-data.html

2. Saker L, Lee K, Cannito B, Gilmore A, CampbellLindrum D. Globalization and infectious diseases: A review of the linkages. Special Topics in Social, Economic and Behavioural (SEB) Research Special Topic No.3. 2004. Available from: https://www.who.int/tdr/publications/documents/seb _topic3.pdf

3. Science Daily. Scripps Research Institute. 2020. COVID19 coronavirus epidemic has a natural origin.

Available from:

wWw.sciencedaily.com/releases/2020/03/2003171754 42.htm

4. Guan W, Ni Z, Hu Y, et al. Clinical characteristics of coronavirus disease 2019 in China. New Engl J Med. 2020. https://doi.org/10.1056/NEJMoa2002032

5. Borg MA. Cultural determinants of infection control behaviour: understanding drivers and implementing effective change. J Hosp Infect. 2014. 86:3, 161168.2014. doi: https://doi.org/10.1016/j.jhin.2013.12.006

6. Lakshmi Priyadarsini, S. \& Suresh M. (2020) Factors influencing the epidemiological characteristics of pandemic COVID 19: A TISM approach, International Journal of Healthcare Management, 13:2, 89-98, DOI: $10.1080 / 20479700.2020 .1755804$

7. Montillo-Burton, E. (1996). Disease and History in the Philippines, Current Anthropology 37:3, 578. https://doi.org/10.1086/204527

8. Center for Disease Prevention and Control. Coronavirus Disease 2019 (COVID-19): How It Spreads. 2020. Available from: https://www.cdc.gov/coronavirus/2019ncov/prepare/transmission.htmleCDC_AA_refVal=http s\%3A\%2F\%2Fwww.cdc.gov\%2Fcoronavirus\%2F2019ncov\%2Fabout\%2Ftransmission.html

9. Thompson WW, Shay DK, Weintraub E, Brammer L, Cox N, Anderson LJ, Fukuda K. Mortality associated with influenza and respiratory syncytial virus in the United States. JAMA. 2003 Jan 8;289(2):179-86. doi: 10.1001/jama.289.2.179. PMID: 12517228.

10. Infectious Disease News. Comorbidities, metabolic changes make elderly more susceptible to infection. 2011. Available from: 
https://www.healio.com/infectious-

disease/news/print/infectious-disease-

news/\%7Ba029cda7-ca04-4ble-98ae-

677d27670ceb\%7D/comorbidities-metabolic-changesmake-elderly-more-susceptible-to-infection

11. World Health Organization. Report of the WHO-China Joint Mission on Coronavirus Disease 2019 (COVID-19). 2020. Available from:

https://www.who.int/docs/default-

source/coronaviruse/who-china-joint-mission-on-

covid-19-final-report.pdf

12. Zhang JJ, Dong $X$, Cao $Y Y$, Yuan $Y D$, Yang $Y B$, Yan $Y Q$, at al. Clinical characteristics of 140 patients infected with SARS-CoV-2 in Wuhan. Allergy. 2020. doi: https://doi.org/10.1111/all.14238

13. Lunzen J, Altfeld M. Sex Differences in Infectious Diseases-Common but Neglected. J Infect Dis. 2014; 209 (3), pp S79-S80, https://doi.org/10.1093/infdis/jiu159.

14. Nhamoyebonde S, Leslie A. Biological Differences Between the Sexes and Susceptibility to Tuberculosis. J Infect Dis. 2014; 209 Suppl 3. S100-6. doi: https://doi.org/10.1093/infdis/jiul 47.

15. World Health Organization. Addressing sex and gender in epidemic-prone infectious disease. 2007. Available from:

https://www.who.int/csr/resources/publications/SexG enderlnfectDis.pdf

16. Institute of Medicine (US) Committee on Understanding the Biology of Sex and Gender Differences; Wizemann TM, Pardue ML, editors. Exploring the Biological Contributions to Human Health: Does Sex Matter? Washington (DC): National Academies Press (US); 2001. Available from: https://www.ncbi.nlm.nih.gov/books/NBK222288/ doi: $10.17226 / 10028$

17. Zhao $Y$, Zhao Z, Wang Y, Zhou Y, Ma Y, Zuo W. Singlecell RNA expression profiling of ACE2, the putative receptor of Wuhan 2019-nCov. bioRxiv. 2020. DOI:10.1101/2020.01.26.919985. Available from: https://www.biorxiv.org/content/10.1101/2020.01.26.91 9985v1.full.pdf+html 